REVIEW

\title{
Resuscitation of the preterm infant against parental wishes
}

\author{
J J Paris, M D Schreiber, A Elias-Jones
}

Arch Dis Child Fetal Neonatal Ed 2005;90:F208-F210. doi: 10.1136/adc.2004.063420

Over the past 40 years, the norms on who is to make treatment decisions for newborns, and on what standards, have been significantly altered and revised. Today the standard for treatment of newborns is the "best interest" of the child. A recent ruling of the Texas Supreme Court authorising a doctor to resuscitate a potentially viable very premature newborn over the parents' objection is a challenge to that standard.

I $\mathrm{n}$ a recent commentary in The New England Journal of Medicine, George Annas reviews a Texas Supreme court opinion, Miller v HCA, in which that court became the first to authorise a physician to resuscitate an extremely premature infant over parental objections. ${ }^{1}$ The case raises anew an issue that the EPICure study describes as among the most difficult and trying clinical problems for obstetricians and paediatriciansthe care of the fetus considered to be at the threshold of viability. ${ }^{2}$ More specifically, it examines one of the unresolved questions in that area: who decides for the extremely premature newborn, and on what basis, when there is a conflict between parents and physicians?

Although over the past 40 years, the norms on who is to make these treatment decisions and on what standard have been significantly altered and revised, ${ }^{3}$ there is now a strong consensus in the medical and bioethics community that for extremely premature infants-where the risk of mortality or morbidity is significant and the prospects of benefit is suffused in ambiguity and uncertainty - the decision on whether or not to institute medical treatment properly belongs to the parents. Reflecting on that consensus, Jerold F Lucey, the Editor in Chief of Pediatrics, recently wrote, "We should admit how little we know, explain the present bleak outlook, and ask [the parents] for their help. Some will choose active resuscitation, others will not." ${ }^{4}$ The widespread agreement in both North America and the United Kingdom with that approach has come under challenge with the Texas Supreme Court's ruling in Miller v HCA. ${ }^{5}$

See end of article for authors' affiliations ....................

Correspondence to: Professor Paris, Department of 'Theology, Boston College, Chestnut Hill, MA 02467, USA; john.paris@bc.edu

Accepted 18 January 2005

Accepted 18 January 2005 neonatologist informed the parents that there was little chance of the infant being delivered alive. They also informed the parents that if the child were born alive, "it would most probably suffer severe impairments, including cerebral palsy, brain hemorrhaging, blindness, lung disease, pulmonary infections and mental retardation."

With that background, the obstetrician and neonatologist asked the parents whether they wanted their infant daughter treated aggressively if, as anticipated, they would have to induce delivery. The parents informed the doctors that they did not want any attempts at treatment. The parents' decision was recorded in the medical record, and the obstetrician informed the medical staff that no neonatologist would be needed at the delivery.

After the parents' decision had been agreed to, someone on the nursing staff informed other hospital personnel that no neonatologist would be present for the delivery. At a meeting called to discuss objections to that decision, the administrator of the neonatal intensive care unit stated that hospital policy required resuscitation of any baby weighing over $500 \mathrm{~g}$. (A later investigation revealed that, although the statement had been made, no such law or policy existed). Once that claim had been made, it was agreed by the staff that a neonatologist would be present at the delivery to assess the baby's age and weight. To prevent further compromise to the mother's condition, labour inducing drugs were administered. Some 11 hours later Kara Miller delivered a 23.1 week gestational age infant girl weighing $615 \mathrm{~g}$. The neonate was limp, blue, had a "below normal" heart rate, but gasped for air and cried spontaneously. The infant was immediately "bagged," intubated, and placed on a ventilator. The Apgar scores were 3 at one minute and 6 at 10 minutes.

At some point during the first days of life, the infant suffered a significant brain haemorrhage which, in the Court's words, "caused [her] to suffer severe physical and mental impairments." The Court described her condition at the time of trial as: "[S]he was seven years old and could not walk, talk, feed herself, or sit up on her own. [She] was legally blind, suffered from mental retardation, cerebral palsy, seizures, and spastic quadriparesis in her limbs. She could not be toilet-trained and required a shunt in her brain to drain fluids that accumulate there and needed care twenty-four hours a day. The evidence further demonstrated that her circumstances will not change."

The Millers sued the hospital and its parent corporation Columbia/HCA Healthcare Corporation (HCA), the largest for-profit healthcare system in the United States. A jury found that the hospital, 
without the consent of the parents, had resuscitated their infant. It also found that negligent action was the cause of their daughter's injuries. The jury awarded the family \$29 400000 in actual damages for medical expenses, \$17 503066 in prejudgment interest, and \$13 500000 in punitive damages. The latter payment was designed as punishment for improper behaviour of the hospital and a deterrent to others from engaging in similar behaviour. The jury verdict was overturned by the Texas Supreme Court.

\section{TEXAS SUPREME COURT OPINION}

The Texas Supreme Court posed the question raised in Miller v HCA as follows: "This case requires us to determine the respective roles that parents and health care providers play in deciding whether to treat an infant who is born alive but in distress and is so premature that despite advancements in neonatal care, has a largely uncertain prognosis." In arriving at that question, the Court relied heavily on the testimony of the neonatal fellow who had attended the delivery as to why he had overridden the parents' refusal of treatment. When asked if he could predict where on the continuum from stillborn to a normal child the Miller child would fall, the neonatal fellow replied, "No." He then continued, "This is a baby that is not necessarily going to have problems later on. There are babies that survive at this gestational age-with this birth-weight - that go on and do well."

Consent in cases involving infants has till now been the prerogative of the parents. The state, acting as parens patriae, can and does intervene to protect children from neglect and abuse or to prevent parental choices that would produce such results. ${ }^{6}$ But as long as parents choose from a professionally accepted option, the choice is rarely challenged or supervened. The Texas Supreme Court acknowledged that parental role, but in this instance the Court ruled that when a doctor is confronted in a case where there are "emergent circumstances" - that is, where death of a child is likely to result immediately unless treatment is administered-he/she can intervene even over parental objections.

The Texas Court, citing the testimony of the neonatal fellow, ruled that the infant "could only be properly evaluated when she was born." Consequently, in the Court's view, "Any decision by the Millers before [the infant's] birth would necessarily be based on speculation." Further, the Court opined, a pre-delivery decision would "not have been a fully informed one." As the Texas Supreme Court saw it, the doctor present at the delivery had to make "a split second decision on whether to provide life-sustaining treatment." In that situation, it held, "there simply was no time to obtain [the parents'] consent to treatment or to institute legal proceedings to challenge their withholding of consent without jeopardizing [the infant's] life."

\section{DISCUSSION}

This is a ruling of enormously sweeping scope, albeit in a narrowly circumscribed situation. It applies, as the Court would have it, only to children and "only when there is no time to consult the parents, or seek court intervention if the parents withhold consent before death is likely to result." In reaching that conclusion, the Texas Supreme Court rejected the policies of the American Academy of Pediatrics ${ }^{7}$ and the "Good Medical Practice" guidelines of the Royal College of Paediatricians and Child Health $(\mathrm{RCPCH})^{8}$ of counselling parents on the survival and outcome prospects of strikingly premature deliveries and involving them in decisions for their infants. And although Lord Donaldson in In Re $\mathrm{R}^{9}$ highlighted the doctor's duty to treat in an emergency without consent if in the doctor's judgment such a treatment would be in the best interests of the child, in the case of a baby with only a small chance of survival and even then with a high risk of handicap, it would not be unreasonable under the standards of the RCPCH's Framework of practice sections on "No purpose" or the "Unbearable situation" not to initiate resuscitation. ${ }^{10}$

The "facts" adopted by the Texas Supreme Court from statements given at the trial by the neonatology fellow who attended the delivery of Baby Miller are strikingly at variance with the data found in the literature on mortality and morbidity of 23 week gestational age infants. Further, they do not reflect the general practice of neonatologists regarding delivery room decisions for infants at the threshold of viability. A recent survey of level $2 / 3$ neonatologists by Harvard researchers reveals that "at or below 23 0/7 weeks gestation $93 \%$ of respondents considered treatment futile."11 At 23 1/7-6/7 weeks gestation, almost $90 \%$ of respondents considered treatment to be of uncertain benefit-that is, neither clearly beneficial nor futile. In those circumstances, the overwhelming majority $(76 \%)$ stated that they would follow the parents' decision to forego treatment and allow such infants to die. There was a similar response to a United Kingdom survey of paediatricians/neonatologists which found that, at less than 23 weeks gestation and under $500 \mathrm{~g}, 85 \%$ would be deterred from resuscitation. ${ }^{12}$

A helpful framework for decision making in these types of cases is found in an essay by Tyson and colleagues ${ }^{13}$ on viability and morbidity of very low birthweight neonates. Rather than an either/or designation of parent or doctor as the decision maker, the authors propose that the treatment options should be governed by the prospects for the individual infant. To make that assessment, the authors divide treatment decisions for newborns into four categories: mandatory, optional, investigational, and unreasonable. They are explained as follows.

- Mandatory: if the parents ask the physician to withhold or withdraw ventilatory support that has a very high likelihood of benefiting a child, the treating physician's independent obligation to foster the best interests of the patient prohibits following the parents' request. An example would be parents who ask the physician to remove ventilation from a full term newborn unless the physician can guarantee that their child will be "normal." ${ }^{14}$

- Optional: when the risks are very high and the benefits are at best uncertain or extremely low, the parents have the option of accepting or rejecting the proposed resuscitation. In this "grey zone" the parents' decision to either accept or reject ventilatory support should be followed. ${ }^{15}$

- Investigational: for resuscitation for babies of very low birth weight, the outcome data are such that, in the words of Lantos et al, "The best we can tell parents is that this intervention is so new or its effects on this class of patients so unproven that it is an 'innovative' or 'experimental' procedure." ${ }^{16}$ Such procedures, as the Nuremberg standards inform us, necessarily require patient or proxy consent.

- Unreasonable: if the parents are demanding attempts at resuscitation, when in the physician's best judgment there is no expectation of efficacy-for example, on a child born with Potter's syndrome or a 20 week, 298 g delivery, there is no obligation to attempt resuscitation. Indeed to attempt resuscitation or other medical treatment when there is no possibility of benefit to the patient would constitute an assault or battery. ${ }^{17}$

A newborn's prospects vary from the complete uncertainty of a "normal" future for a full term baby experiencing a postdelivery respiratory episode, to the very high probability of mortality and significant morbidity awaiting a 23 week $614 \mathrm{~g}$ infant. The EPICure study, for example, reports a survival rate to discharge at 23 weeks - the age of the Miller child-of $11 \%$. The most recent outcome data on extremely premature 
infants, the 2004 Vermont/Oxford Network study of 4172 infants born with very, very low birth weights, notes an increase in the percentage of survivors $(17 \%)$, but in the words of the authors, the results are "not encouraging." ${ }^{18}$ The vast majority $(83 \%)$ died before discharge, and over half of those $(52 \%)$ did so in the delivery room. Those who did survive almost always suffered from severe complications. As the effectiveness of neonatal intensive care technology for this class of newborns is "essentially unknown," the authors conclude that treatment of those infants is "a large, uncontrolled experiment."

Contrary to the ruling of the Texas Supreme Court, ventilation is not necessarily justified simply because it offers a modest chance of survival. As Francis Moore, the distinguished Harvard surgeon, reminds us, imposing a medical procedure on a patient requires a greater justification than mere survival. In his words, "There must be a rationale on which the desperately ill patient may be offered not merely pain, suffering and cost, but also true hope of prolonged survival [without devastating sequelae]."19

Although clearly premature infants will die without mechanical ventilation, the decision whether or not to initiate resuscitation ought not be based solely on a doctor's assessment of potential viability. Survivability is not the only issue at stake. Although death is unquestionably a bad outcome, imposing mechanical ventilation can make for a worse situation-demise after days or months of predictable morbidity so severe it might be judged an even greater tragedy than death. ${ }^{20}$

To avoid that possibility, resuscitation decisions for extremely premature neonates should be based on the prospects for a particular child. To achieve that goal, as the EPICure study group put it, professionals must provide parents with "reliable outcome data based on gestational age that will allow the parents to plan care around the time of birth." Evaluating the significance of those data in an individual case and determining whether or not the risks and benefits warrant the use of aggressive technology is a value judgment, not a medical assessment. As such, it properly belongs to those who, along with the infant, will bear the burden of a decision to resuscitate: the parents.

\section{CONCLUSION}

The Miller case confirms the adage that "bad facts make bad law." The mis-statement of institutional policy by a hospital administrator led the medical staff to abandon the well thought through parent-physician decision to omit resuscitation of an infant at the very margins of viability, a decision that was well within the standard of care. The determination to resuscitate was based on the mistaken belief that the law required the resuscitation of any infant with a delivery weight $>500 \mathrm{~g}$. The record does not indicate why once the child was resuscitated and subsequently suffered significant neurological insult that the use of aggressive medical interventions was not re-evaluated and discontinued.

The only issue raised in the case and addressed by the Texas Supreme Court was whose decision is it to determine whether or not to omit resuscitation for an extremely premature infant. In the Court's view, that role belongs exclusively to the physician. The Court did not mandate that physicians resuscitate all potentially viable newborns. It did, however, authorise physicians to decide whether or not to resuscitate in these cases when the outcome is "essentially uncertain and when failure to resuscitate would result in the infant's death." In such instances, the physician may resuscitate the extremely preterm infant even over parental objections.

In the United Kingdom when there is disagreement between the medical staff and the parents and the opinion of a court has been sought, such as in the recent cases of
Charlotte Wyatt ${ }^{21}$ and Luke Winston-Jones, ${ }^{22}$ judges have normally ruled in favour of the medical viewpoint, and have applied the RCPCH framework for practice as in the "no chance situation" applied with Baby C with spinal muscular atrophy type $1 .{ }^{23}$ Only rarely has the sincerely held view of caring parents won the ruling against unanimous medical opinion. ${ }^{24}$ However, in the Miller case it appears as though the disagreement was less with the parents than between members of the medical and nursing staff involved. And although it might have been reasonable for the neonatal fellow in the obstetrical suite to have opted to resuscitate on the basis of a post-delivery assessment of potential viability, there appears to have been no attempt to reassess the clinical situation and the likely outcome after birth, particularly when a major intraventricular haemorrhage had been identified.

The danger with the Texas Supreme Court's ruling in Miller v HCA is that, under it, a physician who wants to resuscitate a neonate may do so no matter how premature, how unlikely to survive, how likely to incur severe disabilities, or how strongly the parents object. This substitution of the physician's values for those of the parents of infants delivered at the extreme margins of viability is a significant shift from present standards in neonatology. We believe such a change is neither good policy nor good medicine.

\section{Authors' affiliations}

J J Paris, Boston College, Chestnut Hill, MA 02467, USA

M D Schreiber, Department of Pediatrics, University of Chicago

Children's Hospital, Chicago, IL 60637, USA

Alun Elias-Jones, Leicester General Hospital, Leicester LE5 4PW, UK

Competing interests: none declared

\section{REFERENCES}

1 Annas GJ. Extremely preterm birth and parental authority to refuse treatment: the case of Sidney Miller. N Engl J Med 2004;351:2118-23.

2 Costeloe K, Hennessey E, Gibson AT, et al. The EPICure study: outcomes to discharge from hospital for infants born at the threshold of viability. Pediatrics 2004; 106:659-71.

3 Paris JJ. From the Johns Hopkins Baby to Baby Miller: What we have learned from four decades of reflection on neonatal cases. J Clin Ethics 2001;12:207-14. 4 Lucey JF. Fetal infants: thoughts about what to do. Pediatrics 2004; 113:1819.

5 Miller v HCA, Inc. 118 S.W. 3rd 75, 2003.

6 Studdent DM, Mello DM, Brennan TA. Medical malpractice. N Engl J Med 2004;350:283-92

7 American Academy of Pediatrics Committee on Fetus and Newborn, American College of Obstetrics and Gynecologists Committee on Obstetric Practice. Perinatal care at the threshold of viability. Pediatrics 1995;96:974-6.

8 Royal College of Pediatrics and Child Health. Good medical practice in pediatrics and child health: duties and responsibilities of pediatricians. London: RCPCH, 2002.

$9 \operatorname{Re}(\mathrm{R}) 7 \mathrm{BMLR} 147$ at 158, 1991

10 Royal College of Pediatrics and Child Health. Witholding and withdrawing life sustaining treatment in children: a framework for practice, 2nd ed. London: RCPCH, 2004.

11 Peerzada JM, Richardson DK, Burns JP. Delivery room decision-making at the threshold of viability. J Pediatr 2004;145:492-8.

12 Elias-Jones AC. Legal implications of the withdrawal of neonatal intensive care. University of Wales Library, 1996.

13 Tyson JE, Younes N, Verter J, et al. Viability, morbidity, and resource use among newborns of 501- to 800-g birth weight. JAMA 1996;276:1645-51.

14 Paris JJ, Bell AJ. Guarantee my child will be "normal" or stop all treatment. J Perinatol 1993;13:469-72.

15 Paris JJ, Newman V. Ethical issues in the quadruple amputation of a child with meningococcal shock. J Perinatol 1993;12:56-8.

16 Lantos J, Miles SH, Silverstein MD, et al. Survival after cardiopulmonary resuscitation in babies of very low birthweight. N Engl J Med 1988;318:91-5.

17 Airedale NHS Trust $v$ Bland AC 789 at 883, 1993.

18 Lucey JF, Rowan CA, Shiomo P, et al. Fetal infants: the fate of 4172 infants with birth weights of 401 to 500 grams - the Vermont Oxford Network experience (1996-2000). Pediatrics 2004;113:1559-6.

19 Moore F. The desperate case: CARE (costs, applicability, research, ethics). JAMA 1989;261:1483-4.

20 Mitchell C. When living is a fate worse than death. Newsweek 20 Aug 2000:12.

21 Gibb F. Child's best interests guided judge. The Times 8 Oct 2004;3DC:5

22 Peek L. Judge says doctors can deny baby ventilation. The Times 23 Oct 2004;3C:10.

$23 \operatorname{Re}$ C FLR 135, 1998.

$24 \operatorname{Re} T$ (A minor) (Wardship: medical treatment) 35 BMLR 63 (CA), 1996. 